6. Московский Г.А. Пермский галогенез Прикаспия: Автореф. дис... д-ра геол.-минерал. наук. Воронеж, 2000. $36 \mathrm{c}$.

7. Петриченко О.И. Физико-химические условия осадкообразования в древних солеродных бассейнах. Киев, $1988,128 \mathrm{c}$.

8. Московский Г.А., Свидзинский С.А. Соотношение ритмопачек и циклов седиментации в галогенных разрезах Северного Прикаспия // Советская геология. 1989. № 5. C. 49-54.

9. Валяшко М.Г., Петрова И.С. Использование брома и рубидия в качестве геохимических индикаторов при оценке генезиса калийных солей // Бром в соляных отложениях и рассолах. М., 1976. С. 418-427.

УДК [626.34 : 551.435 .1$](470.44-25)$

\title{
ЕСТЕСТВЕННАЯ И ИСКУССТВЕННАЯ ДРЕНАЖНЫЕ СЕТИ ТЕРРИТОРИИ САРАТОВА: СОВРЕМЕННОЕ СОСТОЯНИЕ И СООТНОШЕНИЕ
}

\section{И.А. Яшков, Г.И. Худяков ${ }^{1}$, А.В. Иванов \\ Саратовский государственный университет, кафедра геоэкологии \\ E-mail: YashkovlA@mail.ru \\ ${ }^{1}$ кафедра геоморфологии и геоэкологии \\ E-mail: geomorph@sgu.ru}

В статье рассматриваются основные проблемы современного функционирования городской дренажной сети. Проведен анализ геоэкологического состояния отдельных участков городской эрозионной и ливневой систем. Предлагается ряд мер для оптимизации коэволюции естественной и искусственной дренажных сетей на примере территории Саратова.

Natural and Artificial Drainage Networks of Saratov: Modern State and Relation

\section{I.A. Yashkov, G.I. Khudyakov, A.V. Ivanov}

Problems of modern urban drainage network functioning have been considered. Analysis of geoecological state of separate regions of urban erosive and drawn systems has been carried out. An approach to the optimization of natural and artificial drainage networks has been suggested by the example of Saratov territory.

\section{Введение}

В настоящее время в условиях стремительного роста и усложнения урбанизированных территорий различные геоэкологические процессы, негативно влияющие на нормальное функционирование городских систем, приобретают прогрессирующий характер. Для территории Саратова такими главными негативными геоэкологическими эффектами являются подтопление и оползневые процессы. Среди основных причин, стимулирующих активизацию этих процессов в городе, можно назвать следующие:

1) геолого-геоморфологические (подъем уровня грунтовых вод, относительно слабая дренированность территории, подмыв берегов водохранилища и др.);

2) инженерно-технические (давление жилых, промышленных и транспортных систем и сооружений на литогенную основу города; за-

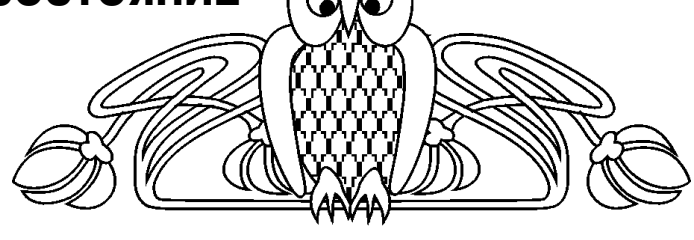

стройка жилыми и промышленными зданиями и сооружениями несогласно основным уклонам поверхности геоморфологических структур и соответственно поперек естественному стоку поверхностных и грунтовых вод; порывы водонесущих трубопроводных сетей и утечка бытовых, технических и канализационных вод в почвогрунты и др.).

Одним из основных элементов городской поверхностной структуры, обеспечивающих ее функционирование, являются естественная и искусственная дренажные сети - своего рода «кровеносная система» городского «организма». Под естественной дренажной сетью (ЕДС) будем понимать всю систему эрозионной сети на урбанизированной территории, включающей в себя долины рек, балок и оврагов и их более мелких, соподчиненных им, элементов: ложбин, промоин, рытвин. Искусственная дренажная сеть (ИДС) включает в себя городскую ливневую канализацию и дренажные сооружения.

В настоящее время в развитии урбанизированной системы Саратова наблюдаются определенные закономерности и процессы, которые сильно влияют на всю работу, выполняемую ЕДС и ИДС. По мере развития городской территории нагрузка на общую систему дренажных сетей постоянно растет. За последние два-три десятилетия в динамике развития дренажной сети происходят негативные процессы, связанные с естественным и антропогенным нивелированием городского рельефа, уничтожением эрозионной сети в результате застройки, засыпки техногенным материалом и замусоривания долин рек, оврагов и недостаточным строительством новых линий ливневых коллекторов и дренажей.

Предпосылкой выработки стратегии оптимизации функционирования ЕДС и ИДС городских территорий являются следующие комплексные геоэкологические и эколого-геологические исследования изучаемых объектов. 
Изучение геолого-геоморфологических закономерностей развития городской дренажной системы.

Изучение физико-географических и геоэкологических особенностей развития городской дренажной системы.

Изучение влияния геоэкологических особенностей городских территорий на эволюцию овражных комплексов.

Коэволюционные предпосылки взаимодействия ЕДС и ИДС урбанизированных территорий.

\section{Функционирование естественной дренажной сети}

В результате урбогенеза эрозионная сеть на территории Саратова, существующая уже более 400 лет, претерпела значительные изменения. Некогда крупные долины Глебучева, Белоглинского, Токмаковского и других оврагов прорезали город, расчленяя его на кварталы бедняков и богатых. В их устьевые части могли заходить небольшие речные суда. В настоящее время средняя мощность насыпных грунтов в эрозионных, в основном транзитных, формах рельефа в центральной части города достигает 1-3 м, а в долине уже исчезнувшего и потерявшего свои былые функции Белоглинского оврага и в отдельных участках долины Глебучева оврага - до 10 м [1]. В целом в развитии современной овражно-балочной сети территории Саратова идут два взаимосвязанных процесса естественного и антропогенного нивелирования. Первый происходит в результате засыпки и загаживания людьми эрозионных долин, более мелкие их порядки в своих верховьях «застывают», приспосабливаясь к новому, более высокому, базису эрозии, также обрастая при этом техногенным и бытовым мусором. Второй процесс обусловлен прогрессирующим ростом городской территории за счет разравнивания новых площадей земли под строительство зданий и сооружений (порой хаотично расположенных), прокладки новых дорог, повторного асфальтирование уже существующих транспортных сетей и т.д. Свою лепту вносит также применение свайного метода во время строительства фундаментов многоэтажных домов при расположении их поперек основному естественному стоку поверхностных и грунтовых вод. В результате действия всех этих факторов водный поток, перемещаясь по естественным уклонам геоморфологических структур города, вынужден искать новые пути разгрузки, проникая в подвалы (а порой и в нижние этажи) жилых домов и зданий, разрушая фундамент и стены, разбивая асфальтовое покрытие дорог (рис. 1), подмывая опоры линий электропередач. Серьезная опасность кроется в строительстве крупных многоэтажных домов, фундамент которых нередко закладывается одной частью на коренном склоне, а другой - на насыпном грунте. Такие участки долин оврагов и балок являются крайне неустойчивыми. На них развиты различные просадочные и микрооползневые процессы, особенно на контактах коренных пород и насыпных грунтов. Через некоторое время здания, построенные на таком месте, могут дать трещины и перекосы, а в конечном итоге - усилятся процессы разрушения, начиная с фундамента. Примером могут служить проявления оползневого процесса в районе ул. Посадского. Большая часть жилых домов на склоне несколько лет назад была деформирована, в опасной зоне находятся дома №108, №112 (угол ул. Некрасова). В настоящее время в динамике оползня наблюдается относительное равновесие. Еще одним примером взаимосвязи эрозионных процессов и активной оползневой деятельности являются районы садово-огородных участков и дачных поселков на территории Саратова, где в результате наложения комплекса антропогенных и природных факторов масштабы геоэкологических катастроф и риск проживания в этих зонах людей с каждым годов сильно возрастают. Проявление подобных процессов на склонах долины Гуселки, где также наблюдается активизация оползневых процессов, в частности развитие новой крупной оползневой системы, уже приведшее к разрушению отдельных кирпично-бетонных двухэтажных домов, иллюстрирует рис. 2. Причинами активизации оползневых процессов являются преимущественно антропогенные факторы: неумеренный полив садов и огородов на территории зоны оползневой опасности, прокладка и активная эксплуатация грунтовой дороги с щебневой насыпкой (что вызывает повышенную вибрацию, уплотнение грунта, повышение механической нагрузки). Сошедший оползень своим языком частично перегораживает русловую часть р. Гуселки, что вызывает образование заболоченных участков. Хорошо наблюдаются явления «пьяного леса», дальнейшего растрескивания сползших элементов. Есть все основания прогнозировать, что оползень в ближайшие годы, вырабатывая профиль равновесия, активно продвинется в глубь левого берега реки, осложнится новыми блоками и чешуями, что повлечет за собой разрушение дороги и дачного массива. В качестве предупредительных мер необходимы регулирование полива, запрет эксплуатации дороги большегрузным транспортом, а также желательно ликвидировать ближайшие к оползню садоводческие участки.

\section{Функционирование искусственной дренажной сети}

При анализе современного состояния ИДС Саратова использовались в основном официальные документы, данные СМИ (опубликованные газетные статьи, интервью работников административных служб), web-сайтов Интернета, а также маршрутные наблюдения. Научных публикаций и фондовых материалов, специально 


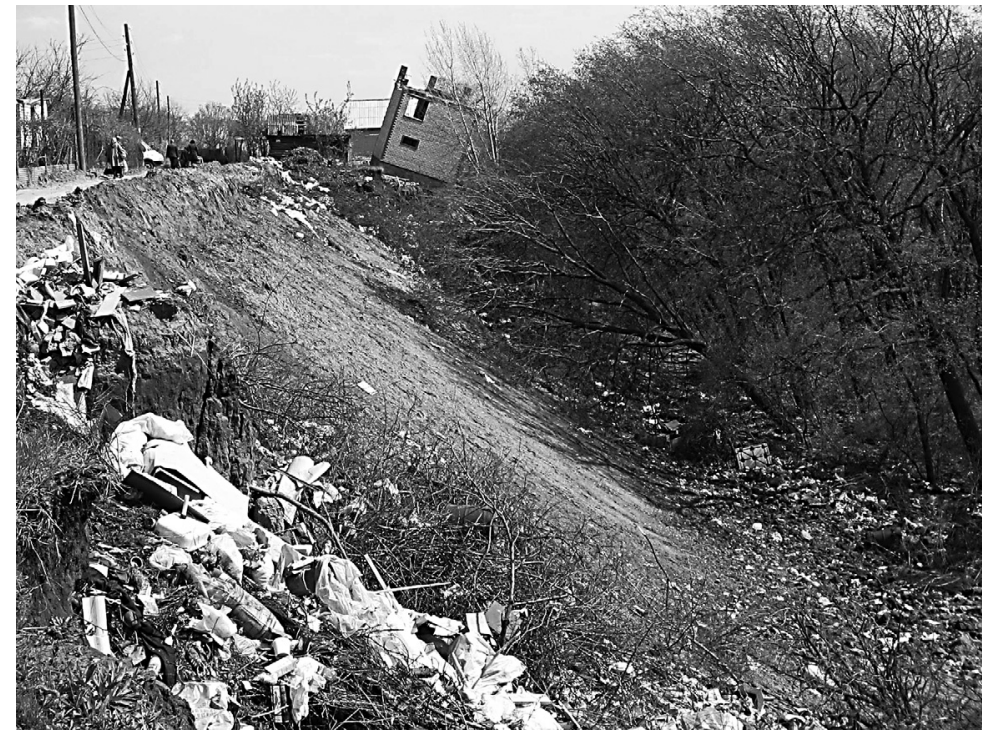

Рис. 2. Последствия схода оползня в долине р. Гуселки (Саратовский участок). Фотография И.А. Яшкова, 2006 г.

этот песочно-бытовой материал попадает через решетки коллекторов в городскую ливневую сеть. Очистить от него ливневки можно только вручную с применением ведер, багров и лопат.

Одной из причин тяжелого состояния ливневой канализации Ю.А. Соседов называет износ дренажных сетей на 90\% при их эксплуатации около 30 лет. До сих пор остается сложной ситуация и с определением юридической принадлежности городской ливневки. Когда несколько лет назад МУП «Водосток» брал ливневки на баланс, их было всего 20 км. За время работы были найдены еще 180 км. Но на большинство коллекторов нет даже проектной документации [4]. В МУП «Водосток» в настоящее время занимаются не только вопросом очистки ливневых канализаций, но и «поиском» забытых, засыпанных и разрушенных коллекторов. За все время существования городской ливневой сети (начиная со второй половины XIX в.) было утеряно много документации, в которой отражались схемы и планы существующих дренажей, сами они переходили «из рук в руки» различных административных учреждений.

Интересно по этому поводу рассуждает в своей статье [5] историк и журналист Д. Чернышевский: «"Водная” проблема Саратова имеет давние корни. Уходит она ещё во вторую половину XIX-начало XX в., когда «на болоте» был застроен район Крытого рынка. Но в то время к воде относились серьезнее, вкладывали деньги в строительство дренажных систем и водоотводов. Некоторые «царские» водоотводы, заброшенные и забытые, исправно работают до сих пор. «Пойменный» характер саратовских грунтов учитывался и в составленном при Николае II генеральном плане застройки Саратова, на котором предусматривалось сохранить все саратовские овраги, как естественные водосбор- 
ники. Именно овраги (Глебучев, Токмаковский и др.) определили странное направление наших улиц, идущих под углом к Волге: Московская, Немецкая и другие магистрали специально были заложены параллельно оврагам, чтобы отходящие от них уличные застройки упирались в овраги перпендикулярно и «отводили» в них излишки воды. Строили дренажные системы и при Сталине, когда в Саратове проложили 42 км общегородских водоотводов, осушив район от вокзала до ул. Чапаева. Но при Хрущеве про геологию и подземное хозяйство как бы забыли. И с середины 1950-х гг. инженерная защита Саратова была брошена на произвол судьбы. А тем временем заполнилось Волгоградское водохранилище, и уровень подпочвенных вод сделал резкий скачок вверх» [5].

Сейчас, по данным Ю.А. Соседова, специальным бригадам рабочих и специалистов «Водостока» приходится заниматься поиском не только забытых всеми ливневок, но и решеток коллекторов и крышек канализационных люков с помощью миноискателя, так как их замуровывают асфальтовым покрытием при ремонте дорог. Зачастую это делается в корыстных целях. По словам Ю.А. Соседова, администрация города издала распоряжение, согласно которому ливневки возле организаций должны очищать сами предприниматели. К примеру, руководство «Торгового центра» решило просто не тратиться по таким «пустякам». Там ливневки тоже заасфальтировали. Работникам «Водостока» приходится спускать в коллекторы людей и отыскивать люки изнутри. Только за один 2003 г. в Ленинском районе Саратова были обнаружены около ста замурованных колодцев [4].

На современное состояние и функционирование ИДС Саратова оказывают влияние не только выбросы бытового мусора и забивка коллекторов песком. При строительстве новых многоэтажных домов зачастую канализационные трубы подводят прямо к ливневым сетям или выводят непосредственно в долины оврагов (примером могут служить дома пос. Шарковка в Заводском районе, дома по ул. Кавказская в р-не Заводского загса) [4], что представляется «Саратовводоканалу» «экономичнее». Похожая ситуация складывается и в частном жилом секторе Саратова. По данным генерального директора МПП «Саратовводоканал», председателя постоянной комиссии по градостроительству, жилищно-коммунальному хозяйству, архитектуре, земельным ресурсам Л.В. Абрамовой, порядка 30\% частных домовладений не имеют присоединения к системе городской канализации. Это практически весь район Глебучева оврага и частные домовладения на окраинах города».

Поддержание ИДС в городе в более или менее нормальном состоянии, строительство новых ливневок обходится городскому бюджету в десятки миллионов. Проектирование и строительство занимают продолжительное время. За 2002-2004 гг. в Саратове были построены дренаж п. Мирный протяженностью 4 км, лучевой дренаж на пересечении улиц Рахова и Белоглинской, лучевой дренаж в районе музея им. Радищева, ливневой коллектор по ул. Чапаева - 600 п. м., ливневая канализация по ул. Б.Садовой -800 п. м., ливневая канализация по ул. Б.Казачьей - 300 п. м. В 2005 г. велись следующие работы: прокладка дренажа по ул.Первомайской Октябрьского района; прокладка дренажа по ул. Соколовой Волжского района; строительство ливневого коллектора Белоглинского оврага. В 2006 г. велось строительство ливневого коллектора в районе ВСО Ленинского района, ливневой канализации в Заводском районе по ул. Огородной. Строительство одного погонного метра коллектора сечением 500 мм обходится в 8-10 тыс. рублей [2].

В настоящее время все проектные расчеты по строительству новых ливневок находятся в ведении МУП «Водосток», «Саратовгражданпроект» и ООО «Эколайн». По различным данным, для нормального функционирования городской ИДС необходимая длина сети ливневых коллекторов и дренажей должна быть не менее 800-1000 км.

\section{Выводы}

Для разработки первоочередных мероприятий по сохранению и улучшению основных функциональных характеристик элементов общей дренажной сети городской системы, помимо изучения геолого-геоморфологического строения и гидрогеологических особенностей рассмотренной территории, требуется анализ параметров эрозионных бассейнов и имеющихся в их пределах элементов ИДС. Одним из возможных методов является сопоставление схем элементов естественной и искусственной дренажных систем в пределах отдельного водосборного бассейна внутри городской среды, выполненных в крупном масштабе (рис. 3, $a, \sigma)$. Природная эрозионная сеть, представленная в виде системы линий тальвегов, дает наглядную информацию о характере рисунка природной сети и уровне развития современной ливневой канализации. При необходимости возможность корреляции этих схем увеличивается с учетом использования дополнительных характеристик: глубины залегания грунтовых вод, литологического состава геологического субстрата, мощности техногенных грунтов и т.п.

При анализе потенциальной возможности отдельных структурных элементов изучаемых эрозионных бассейнов выполнять функции переноса и разгрузки поверхностного и подземного стока надо учитывать тот факт, что многие тальвеги первых порядков эрозионной сети Глебучева и Белоглинского оврагов в настоящее время засыпаны техногенным материалом, а по долине главного тальвега проложены бетонные коллекторы. Мощность техногенных грунтов на отдельных участках достигает 5-10 м. В этих 


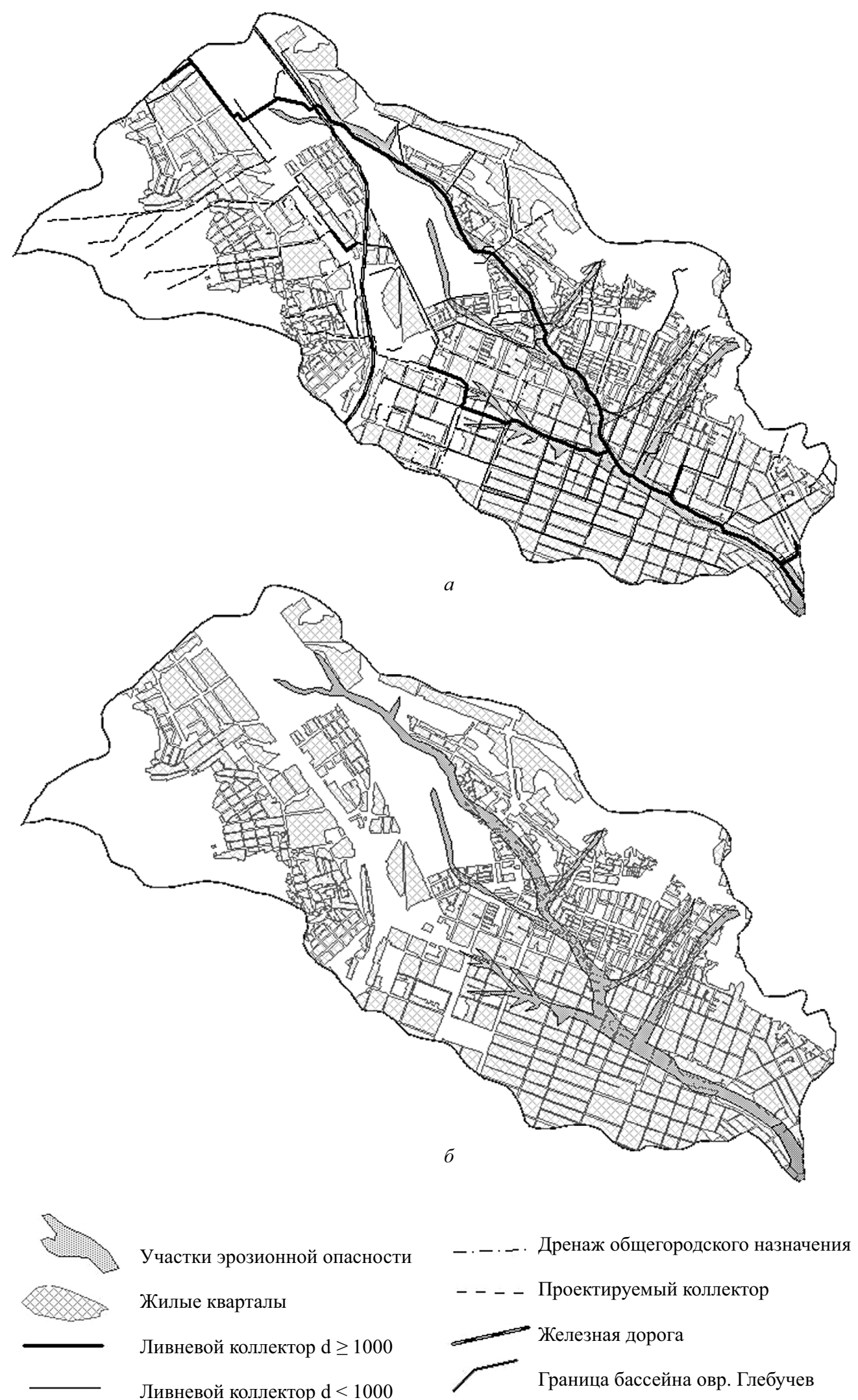

Рис 3. Дренажная сеть бассейна Глебучева оврага: $a$ - схема наложения ЕДС и ИДС; $\sigma$ - реконструированная долинная сеть (Башкатов, 2004 г.) 
условиях ИДС берет на себя основную роль по выполнению функций, которые изначально должны обеспечиваться элементами ЕДС. При разработке проекта и строительстве ИДС инженерами учитываются особенности рельефа и водного баланса территории, необходимые для определения основных направлений заложения коллекторов и их суммарной длины.

Все выше описанные процессы, характерные для современных естественной и искусственной дренажных сетей территории Саратова, происходят в результате закономерного развития городских урбосистем. Основные факторы, ограничивающие нормальное функционирование городской дренажной сети, приведены в табл. 1.

Таблийа 1

Основные факторы, ограничивающие нормальное функционирование городской дренажной сети Саратова

\begin{tabular}{|c|c|}
\hline $\begin{array}{c}\text { Естественная } \\
\text { дренажная сеть }\end{array}$ & $\begin{array}{l}\text { Искусственная } \\
\text { дренажная сеть }\end{array}$ \\
\hline $\begin{array}{l}\text { Естественное и антро- } \\
\text { погенное нивелирование } \\
\text { ЕДС в результате урбо- } \\
\text { генеза }\end{array}$ & $\begin{array}{l}\text { Отсутствие необхо- } \\
\text { димой сети городской } \\
\text { ливневой канализации } \\
\text { (около } 250 \text { км из необхо- } \\
\text { димых } 1000 \text { км) }\end{array}$ \\
\hline $\begin{array}{l}\text { Строительство жилых до- } \\
\text { мов и сооружений, транс- } \\
\text { портных сетей поперек } \\
\text { основному естественно- } \\
\text { му стоку поверхностных } \\
\text { и грунтовых вод }\end{array}$ & $\begin{array}{l}\text { Износ до 90\% всех лив- } \\
\text { невых сетей города }\end{array}$ \\
\hline $\begin{array}{l}\text { Строительство жилых } \\
\text { домов и сооружений, } \\
\text { транспортных сетей на } \\
\text { насыпных грунтах }\end{array}$ & $\begin{array}{l}\text { Неполная рабочая мощ- } \\
\text { ность ливневой сети (до } \\
50 \% \text { от проектных рас- } \\
\text { четов) }\end{array}$ \\
\hline $\begin{array}{l}\text { Малое озеленение овраж- } \\
\text { ных систем }\end{array}$ & $\begin{array}{l}\text { Сброс бытового мусора } \\
\text { и канализационных вод } \\
\text { в коллекторы }\end{array}$ \\
\hline \multirow{3}{*}{$\begin{array}{l}\text { Сброс бытового мусора, } \\
\text { жидких и твердых отхо- } \\
\text { дов в долины оврагов }\end{array}$} & $\begin{array}{l}\text { Незаконные врезы кана- } \\
\text { лизационных труб част- } \\
\text { ного жилого сектора в } \\
\text { городские коллекторы }\end{array}$ \\
\hline & $\begin{array}{l}\text { Отсутствие собственной } \\
\text { дренажной сети под но- } \\
\text { востройками }\end{array}$ \\
\hline & $\begin{array}{l}\text { Замуровывание люков и } \\
\text { решеток коллекторов ас- } \\
\text { фальтовым покрытием }\end{array}$ \\
\hline
\end{tabular}

Влияние урбогенеза не остановить, но его можно оптимизировать через принятие последовательных шагов по сохранению устойчивости этой, так называемой «кровеносной системы», города.

1. Противодействие повышению уровня грунтовых вод:

a) за счет строительства мощной системы дренажей в долинах оврагов и плотно застроенной центральной части города; б) создания биодренажа - посадки деревьев с мощной корневой системой (тополь пирамидальный и дрожащий, ива вавилонская, ушастая, краснотал и др.) в наиболее подверженных процессу подтопления участках города.

2. Перестройка и укрепление жилых и промышленных зданий и территорий (принятие инженерно-технических мер по защите (укреплению) фундамента и стен зданий, строительство дренажа и ливнеотводящих коллекторов).

3. Создание комплекса мер по поддержанию и частичному восстановлению природных функций городской ЕДС:

a) через очистку долин овражно-балочных комплексов и других эрозионных элементов городской структуры от бытового мусора и твердых отходов;

б) строительство новых ливневых коллекторов вдоль улиц, располагающихся поперек склонов оврагов;

в) укрепление склонов оврагов для защиты от проявления на них опасных эколого-геологических процессов (оползней, обвалов, просадок) и др.

Ключевым является вопрос, может ли ИДС замещать ЕДС, выполняя его функции в полной мере в объеме городской урбосистемы? При решении этого вопроса необходимо руководствоваться в первую очередь тем соображением, что вся городская дренажная сеть (ЕДС и ИДС) развивается коэволюционно во времени и пространстве. Для изучения условий оптимального функционирования городской дренажной сети требуется анализ всего комплекса природных и антропогенных факторов, участвующих в процессе ее развития. Для этого нами используются различные геоэкологические и эколого-геоморфологические методы изучения. Исследования носят междисциплинарный характер. В частности, совместно с коллегами с факультета нелинейных процессов СГУ - членкорреспондентом РАН, профессором Д.И. Трубецковым и доцентом А.А. Короновским получены первые результаты по применению фрактального метода для изучения ОБС территории Саратова [6, 7].

Мы выражаем благодарность за консультации профессору В.3. Макарову, В.А. Кононову, сотрудникам МУП «Водосток» Б.М. Дюсамгарову и В.П. Пантелееву, сотруднику ООО «Эколайн» A.A. Вихрову, за помощь в обработке картографического материала - ассистенту кафедры геоморфологии и геоэкологии СГУ А.В. Федорову, а также студентам географического факультета С.В. Усагалиеву и В.А. Кравцовой.

\section{Библиографический список}

1. Саратов: комплексный геоэкологический анализ / С.А.Артемьев, В.Н.Еремин, А.В.Иванов и др.; Под. ред. А.В.Иванова. Саратов, 2003. 248 с. 
2. Шейкин C.B. On-Line конференция // СаратовБизнесКонсалтинг [Электрон. ресурс]. 2005. Режим доступа: http://www.saratovmer.ru/comitets/60/

3. Официальный сайт администрации города Саратова: Управление по инженерной защите города. [Электрон. pecypc]. 2005. Режим доступа: http://www.saratovmer.ru/ comitets $/ 60 /$

4. Алексеев В. Мы все утонем в сточных водах // Толк [Электрон. ресурс]. 2004. Режим доступа: http://www. gazetatolk.ru/N40/n40.htm
5. Чернышевский Д. Город на песке // Саратовские вести. 2000. № 195,

6. Иванов А.В., Короновский А.А., Минюхин И.М., Яиков И.А. Определение фрактальной размерности овражнобалочной сети города Саратова // Изв. вузов. Прикладная нелинейная динамика. 2006. Т.14, №2. С. 64-73.

7. Koronovskiy A.A., Minyuhin I.M., Ivanov A.V., Yashkov I.A. Definition of the fractal dimension of Saratov ravine network // «Problems of Geocosmos» 6-th International Conference, St. Petersburg, Petrodvorets, 23-27 May, 2006. St. Petersburg, 2006. P. 159-160. 